\title{
Educação escolar quilombola no Brasil: uma análise sobre os materiais didáticos produzidos pelos sistemas estaduais de ensino
}

\section{Quilombola school education in Brazil: an analysis of didactic materials produced by state educational systems}

\author{
Elivaldo Serrão Custódio* \\ Eugénia da Luz Silva Foster*
}

\begin{abstract}
RESUMO
O presente artigo tem como objetivo analisar materiais didáticos de Educação Escolar Quilombola (EEQ) da Educação Básica, produzidos especificamente por diferentes sistemas de ensino estaduais no país, confrontando-os com as Diretrizes Curriculares Nacionais (DCN). O trabalho é resultante de pesquisa de pós-doutoramento em Educação pela Universidade Federal do Amapá (UNIFAP), que ocorreu em âmbito nacional no período de 20 de outubro de 2017 a 20 de outubro de 2018. Trata-se de uma pesquisa quali-quantitativa documental reflexiva a partir dos estudos de Minayo (2008), Fonseca (2002), Melucci (2005), Bardin (2002), Larchert e Oliveira (2013), Bittencourt (2007), entre outros. Os resultados da pesquisa apontam que os materiais didáticos analisados apresentaram uma discussão muito restrita e vaga sobre as categorias de análise escolhidas (conceituação de quilombo; cultura e tradições; mundo do trabalho; terra e território; oralidade e memória), limitando-se, muitas vezes, a abordagens superficiais sobre a historiografia do negro no Brasil. Os resultados apontam ainda que esses materiais didáticos produzidos pelos sistemas de ensino estaduais no país atendem, em parte, aos princípios de uma EEQ de qualidade conforme sugerido pelas DCN (2004), deixando, porém, de observar parte dos fundamentos instituídos nas DCN da
\end{abstract}

* Universidade Federal do Amapá. Macapá, Amapá, Brasil. E-mail: elivaldo.pa@hotmail. com. http://orcid.org/0000-0002-2947-5347. E-mail: eugenia.luz@hotmail.com. http://orcid. org/0000-0002-0807-0789. 
EEQ (2012). Além disso, são materiais incipientes com pouca visibilidade e/ ou participação das comunidades quilombolas na elaboração e/ou produção desses materiais, assim também como são deficientes na demonstração das variedades e diversidades étnicas dos quilombos existentes em nosso país.

Palavras-chave: Educação escolar quilombola. Materiais didáticos. Propostas curriculares. Sistemas estaduais de ensino.

\begin{abstract}
This article aims at analyzing didactic materials of Quilombola Elementary School Education (EEQ) of Basic Education produced specifically by educational systems of different states of the country, confronting them with the National Curricular Guidelines (DCN). The work is the result of a postdoctoral research in Education by the Federal University of Amapá (UNIFAP), which took place nationwide in the period of October 20, 2017 to October 20,2018. It is a qualitative and quantitative documentary reflective research of the studies of Minayo (2008), Fonseca (2002), Melucci (2005), Bardin (2002), Larchert and Oliveira (2013), Bittencourt (2007), among others. Additionally, the results of the research show that the didactic materials analyzed presented a very restricted and vague discussion about the categories of analysis chosen (conceptualization of quilombo, culture and traditions, work possibilities, land and territory, orality and memory), being limited to superficial approaches of the historiography of the Negro in Brazil. The results also pointed out that these didactic materials produced by state educational systems in the country meet, in part, the principles of a quality EEQ as suggested by the DCN (2004), however fail to observe some of the foundations established in the EE (2012). In addition, they are incipient materials with poor visibility and/or small participation of quilombola communities in the elaboration and/or production of these materials, as well as deficient in the demonstration of the varieties and ethnic diversities of quilombos in our country.
\end{abstract}

Keywords: Quilombola school education. Teaching materials. Curricular proposals. State education systems.

\title{
Introdução
}

A educação, enquanto ação conjunta, pode provocar posicionamentos em diferentes concepções. Entendida como direito de todos, dever do Estado e da família em colaboração com a sociedade, a educação no Brasil é caracterizada 
pela igualdade de condições, pelo respeito à pluralidade de ideias e pela valorização do patrimônio cultural, ao menos em nível de lei.

A proposta da educação nacional acentua o reconhecimento à diversidade de identidades na valorização do ser humano, e considera no processo, o direito de ser aceito nas especificidades que compõem a nação brasileira. Nesse sentido, percebe-se que a diferença precisa ser levada em consideração em todos os contextos, sendo a escola um dos espaços importantes para colaborar na superação de todas as formas de discriminação e racismo. Sendo assim, as propostas pedagógicas, assim como os regimentos escolares, devem acolher com autonomia e senso de justiça o princípio da identidade pessoal e coletiva dos professores, dos alunos e de todos que convivem nesse espaço social.

Essa compreensão da ação escolar também deve se refletir nas Comunidades Quilombolas, nas quais as instituições de ensino estão inseridas, por meio de seu calendário escolar contemplando atividades curriculares e extracurriculares. Pode, também, promover ampla reflexão sobre a consciência democrática nacional, uma vez que as múltiplas formas de diálogo contribuem para a construção de identidade afirmativa capaz de protagonizar ações solidárias e autônomas de constituição de conhecimento e valores fundamentais para a vida cidadã. Dessa forma, o processo educacional é concebido como indissociável da relação entre conhecimentos, linguagens e afetos constituintes dos atos de ensinar e aprender.

O planejamento curricular escolar assume uma perspectiva que favorece a formação da identidade pessoal e coletiva deste cidadão que estará ligado, e sendo formado, por meio dos saberes da educação básica obrigatória. Garantir que os estudantes possam envolver-se e participar ativamente da sociedade como indivíduos críticos conduzirá a ações que visem uma formação integral, em que todas as suas dimensões sejam desafiadas, superando, assim, o simples acúmulo de informações.

Para assegurar essa área específica de ensino na formação básica do cidadão, é imprescindível garantir amparo legal, definição curricular e formação docente apropriada. Mediante todos os avanços reconhecidos e assegurados em relação à Educação Escolar Quilombola - EEQ (BRASIL, 2010) pela Constituição Federal (BRASIL, 1988), pela Lei de Diretrizes e Base da Educação Nacional - LDB (BRASIL, 1996; 1997) e pelas Diretrizes Curriculares Nacionais - DNC (BRASIL, 2004; 2012), a pesquisa propôs investigar diferentes propostas de referenciais curriculares e de materiais didáticos de EEQ, identificando eixos norteadores na estruturação desse campo específico de ensino e prática pedagógica na educação básica.

Considerando esses pressupostos, compreende-se o diálogo entre os componentes curriculares nacionais e estaduais, com atenção especial para as especificidades regionais e locais. Assim, para este processo, sugerimos a explicitação 
e análise a partir do viés da educação quilombola visando subsidiar o ensino e a prática pedagógica nas escolas públicas quilombolas nos estados brasileiros.

Para a realização da pesquisa, inicialmente fizemos algumas indagações: como está sendo implementada a Lei Federal n 10.639/2003 nos planos curriculares de cada estado brasileiro no que diz respeito à EEQ? Quais as políticas educacionais que cada sistema de ensino estadual vem adotando em favor da EEQ brasileira? Quais estratégias as secretarias estaduais têm utilizado para o combate ao racismo, à discriminação e à intolerância religiosa em seus programas, bem como ações curriculares nas escolas quilombolas observando o impacto no processo civilizador de crianças e jovens quilombolas?

Assim, o presente trabalho tem como objetivo central analisar materiais didáticos (Caderno Pedagógico; Cartilha; Guia pedagógico; Guia metodológico; Orientação Pedagógica; Livro didático) de EEQ da Educação Básica, produzidos especificamente pelos sistemas estaduais de ensino no país, confrontando-os com as DCN.

O artigo é resultante de pesquisa de Pós-Doutoramento em Educação pela Universidade Federal do Amapá (UNIFAP) na Linha de Pesquisa: Educação, Culturas e Diversidades e do Grupo de Trabalho Educação, Relações Étnico-raciais e Interculturais (UNIFAP/CNPq), que ocorreu em âmbito nacional no período de 20 de outubro de 2017 a 20 de outubro de 2018, sob supervisão da professora Dra. Eugénia da Luz Silva Foster (CUSTÓDIO, 2018). Trata-se de uma pesquisa quali-quantitativa documental reflexiva a partir dos estudos de Minayo (2008), Fonseca (2002), Melucci (2005), Bardin (2002), Larchert e Oliveira (2013), Bittencourt (2007), entre outros.

Quanto aos objetivos específicos, a pesquisa se propôs: a) Analisar materiais didáticos de EEQ produzidos especificamente em âmbito estadual pelos diferentes níveis de ensino no Brasil, identificando o espaço destinado nos planos curriculares a temas relevantes à EEQ, tais como: conceituação de quilombo; cultura e tradições; mundo do trabalho; terra e território; oralidade e memória; b) Confrontar diferentes propostas de materiais didáticos estaduais de EEQ com as DCN e a Proposta da Base Nacional Comum Curricular (BNCC); c) Contribuir com reflexão epistemológica e pedagógica acerca da definição curricular da EEQ na educação básica no país.

A pesquisa permitiu um estudo analítico, comparativo e propositivo de maneira colaborativa com distintos agentes dos sistemas de ensino estaduais do país, a fim de estabelecer semelhanças e diferenças em ambos os contextos, no qual foi possível apontar indícios que permitiram dispor de um estado da arte acerca do domínio, bem como uma discussão sobre a produção de materiais didáticos na área da EEQ pelos sistemas de ensino dos estados brasileiros. 
Diante desse contexto, o trabalho se organiza em três seções. A primeira detalha os caminhos e procedimentos metodológicos da pesquisa. A segunda seção descreve os materiais didáticos de EEQ produzidos pelos sistemas estaduais de ensino no Brasil. Na terceira e última seção, mostra-se a análise e compreensão dos materiais didáticos produzidos pelos sistemas estaduais de ensino no Brasil e, por fim, apresentam-se as considerações finais.

\section{Caminho e procedimentos metodológicos da pesquisa}

O estudo iniciou-se com uma pesquisa do tipo bibliográfica, seguida de pesquisa documental de cunho quali-quantitativo por meio de análise reflexiva. Segundo Minayo (2008), o método qualitativo é um método que em seu fundamento permite revelar processos sociais, novas abordagens, conceitos e categorias durante a investigação. Esse método se aplica à apreensão das percepções e opiniões dos grupos ou indivíduos pesquisados, revelando seu cotidiano e sua compreensão do mundo em que vivem.

Já em relação ao método quantitativo, Fonseca (2002) expressa que o enfoque quantitativo diz respeito ao processo de pesquisa baseado na análise de dados brutos, fazendo o uso de linguagem matemática para explicar ou descrever o fenômeno pesquisado. Portanto, compreendemos que a utilização conjunta da pesquisa qualitativa e quantitativa nos permitiu recolher mais informações do que se poderia conseguir em comparação à utilização de ambos os enfoques de maneira isolada.

A perspectiva de pesquisa pautou-se em uma abordagem quali-quantitativo reflexiva, pois Melucci (2005, p. 40) afirma que "[...] nas ciências sociais, o emergir de um ato reflexivo parece estar no centro da atenção como eixo em torno do qual gira a reflexão contemporânea e em torno do qual estão se modificando as práticas de pesquisa". Portanto, a metodologia baseia-se em levantamento e análise de dados a partir de documentos disponíveis e disponibilizados em relação aos referenciais curriculares nacionais, estaduais e materiais didáticos de EEQ.

Quanto à análise dos dados, foram considerados por meio de exame de conteúdo, segundo Bardin (2002), tendo por base o referencial teórico interpretado. Esse referencial esteve presente no diálogo entre as áreas de Educação e História, com um recorte e uma delimitação para a EEQ, atendendo a um olhar especial para os referenciais curriculares e materiais didáticos para essa área de ensino e prática pedagógica. 
Por meio de mapeamento, análise, bem como estudo reflexivo/comparativo de referenciais curriculares e materiais didáticos, investigou-se os eixos norteadores de propostas curriculares de EEQ disponibilizadas no país em interface e confronto com a proposta das DCN de EEQ, no sentido de repensar o processo de formação/atuação docente em estreita vinculação entre o ensino e a pesquisa, confrontando teoria e prática, tanto na formação inicial como na formação continuada, como se pode observar no testemunho de vida do educador Freire (1991) quando afirma que "a gente se forma como educador, permanentemente, na prática e na reflexão sobre a prática”.

A execução da pesquisa aconteceu em âmbito nacional no período de um ano, com início em 20 de outubro de 2017 e término em 20 de outubro de 2018. Diante dos objetivos, buscou-se organizar a pesquisa em três etapas, não consecutivas, mas simultâneas: 1) Na primeira etapa realizamos um levantamento e mapeamento de materiais didáticos de EEQ produzidos pelos estados brasileiros; 2) Na segunda etapa fizemos um estudo analítico, reflexivo e comparativo dos materiais didáticos estaduais em interface e confronto com as DCN de EEQ e as propostas de diretrizes curriculares de cada Estado; 3) Paralelamente a essas duas primeiras etapas da pesquisa, elaboramos e sistematizamos a análise dos dados a partir dos estudos de Bardin (2002).

É pertinente ressaltar que embora saibamos que o Programa Nacional do Livro Didático (PNLD) do Ministério da Educação (MEC) vem produzindo e avaliando diversos livros didáticos no país no que diz respeito à educação para as relações étnico-raciais, que, neste artigo, tanto a pesquisa quanto a análise do material didático, se restringem somente àqueles produzidos pelas instâncias educacionais estaduais.

Quanto às categorias de análise, nesta pesquisa foram utilizados os seguintes termos: a) Conceituação de quilombo; b) Cultura e tradições; c) Mundo do trabalho; d) Terra e território; e) Oralidade e memória. Para cada um desses itens propostos foram utilizadas as letras maiúsculas do alfabeto (A, B, C e D) para indicar os critérios de análise: Amplo (A); Apropriado (B); Restrito (C); Inexistente (D).

\section{Materiais didáticos de EEQ no Brasil: produções dos sistemas estaduais de ensino}

Este tópico apresenta o resultado de um esforço de investigação que incidiu sobre materiais didáticos elaborados pelas Secretarias de Educação, no âmbito 
estadual, no período de 2003 a 2018, em observação à Lei n ${ }^{\circ} 10.639 / 2003$ e Resolução CNE/CEB n ${ }^{\circ}$ 8, de 20 de novembro de 2012, que define as DCN para a EEQ na Educação Básica. O objetivo desta análise foi evidenciar as escolhas curriculares de estados brasileiros, ou seja, identificar e verificar de que forma vem sendo elaborado esse material no espaço de autonomia dos sistemas educativos no que se refere às produções didáticas para a EEQ regional.

Durante o processo de pesquisa física e online, foram utilizadas para consulta na internet as seguintes palavras: Caderno Pedagógico; Cartilha; Guia pedagógico; Guia metodológico; Orientação Pedagógica; Livro didático.

\section{Região Norte}

Em relação à região Norte do Brasil, não foram encontrados materiais publicados sobre a EEQ. Cabe, no entanto, ressaltar que em relação à Secretaria Estadual de Educação do Acre (SEE) encontramos em seu site oficial mais de 40 livros digitais sobre educação indígena, ética, matemática, língua portuguesa, artes, entre outros. No entanto, nenhuma obra que faça referência a EEQ no Estado, a não ser 10 vídeos de educação quilombola de matérias e trabalhos de outros estados. Vejamos o quadro 1 a seguir:

QUADRO 1: PRODUÇÃO DE RECURSOS DA REGIÃO NORTE

\begin{tabular}{|l|l|l|}
\hline \multicolumn{1}{|c|}{ Região } & \multicolumn{1}{|c|}{ Estado } & \multicolumn{1}{c|}{ Documentos } \\
\hline \multirow{4}{*}{ Norte } & Acre & Não há registro \\
\cline { 2 - 3 } & Amapá & Não há registro \\
\cline { 2 - 3 } & Amazonas & Não há registro \\
\cline { 2 - 3 } & Pará & Não há registro \\
\cline { 2 - 3 } & Rondônia & Não há registro \\
\cline { 2 - 3 } & Roraima & Não há registro \\
\cline { 2 - 3 } & Tocantins & Não há registro \\
\hline
\end{tabular}

FONTE: Pesquisa de campo, 2018.

\section{Região Nordeste}

Em relação à região Nordeste do Brasil, não foram encontrados materiais publicados sobre a EEQ, com exceção do Estado do Maranhão que apresentou uma obra composta por 3 volumes: Gestão Escolar, Avaliação da Aprendizagem e Organização Curricular e Práticas de Ensino. Vejamos o quadro 2 a seguir: 
QUADRO 2: PRODUÇÃO DE RECURSOS DA REGIÃO NORDESTE

\begin{tabular}{|c|l|l|}
\hline Região & \multicolumn{1}{|c|}{ Estado } & \multicolumn{1}{c|}{ Documentos } \\
\hline \multirow{5}{*}{ Nordeste } & Alagoas & Não há registro \\
\cline { 2 - 3 } & Bahia & Não há registro \\
\cline { 2 - 3 } & Ceara & Não há registro \\
\cline { 2 - 3 } & Maranhão & $\begin{array}{l}\text { Caderno de orientações pedagógicas: gestão } \\
\text { escolar, 2017. }\end{array}$ \\
\cline { 2 - 3 } & Paraíba & Não há registro \\
\cline { 2 - 3 } & Pernambuco & Não há registro \\
\cline { 2 - 3 } & Piauí & Não há registro \\
\cline { 2 - 3 } & Rio Grande do Norte & Não há registro \\
\cline { 2 - 3 } & Sergipe & Não há registro \\
\hline
\end{tabular}

FONTE: Pesquisa de campo, 2018.

\section{Região Centro-Oeste}

Em relação à região Centro-Oeste do Brasil, não foram encontrados materiais publicados sobre a EEQ nos Estados de Goiás e Mato Grosso do Sul. Por meio do link "Gerência da Diversidade", do portal da secretaria, é possível ter acesso a algumas obras em PDF lançadas em 2010, entre elas sobre EEQ. São oito obras entre livros, livretos, orientações e informações curriculares. Entretanto, apenas um desses documentos é direcionado especificamente à EEQ. Essa obra traz em seu conteúdo temas como: educação em direitos humanos, educação para relações de gênero e diversidade sexual, orientações curriculares de educação ambiental, orientações curriculares para educação das relações étnico-raciais, orientações curriculares para a educação do campo, orientações curriculares para a educação de jovens e adultos e orientações curriculares para a educação escolar indígena.

Quanto ao Distrito Federal, encontramos um guia de Orientação Pedagógica que a Secretaria de Estado de Educação do Distrito Federal vem elaborando, isto é, a secretaria vem instituindo e implementando um conjunto de medidas e ações com o objetivo de corrigir injustiças, eliminar discriminações e promover a inclusão social e a cidadania para todos e todas no sistema de ensino do Distrito Federal. Como expressão do seu compromisso com as políticas afirmativas, apresenta estas Orientações Pedagógicas.

Esse documento é o resultado da política intersetorial dessa gestão governamental que, junto com os profissionais da educação que trabalharam para a implementação dos Artigos 26-A e 79-B da LDB, sistematizou as experiências e transformou em um documento institucional a ser compartilhado com toda a rede de ensino do Distrito Federal. 
Outros objetivos desse documento são, principalmente: (I) Indicar a inserção da educação para as relações étnico-raciais como componente curricular obrigatório em todas as disciplinas do currículo, nas práticas pedagógicas cotidianas e nos projetos escolares; (II) Nortear a inserção da educação para as relações étnico-raciais no Projeto Político Pedagógico (PPP) de todas as instituições educacionais da Educação Básica do Distrito Federal. Vejamos o quadro 3 a seguir:

QUADRO 3: PRODUÇÃO DE RECURSOS DA REGIÃO CENTRO-OESTE

\begin{tabular}{|c|l|l|}
\hline \multicolumn{1}{|c|}{ Região } & \multicolumn{1}{|c|}{ Estado } & \multicolumn{1}{c|}{ Documentos } \\
\hline \multirow{2}{*}{ Centro-Oeste } & Goiás & Não há registro \\
\cline { 2 - 3 } & Mato Grosso & $\begin{array}{l}\text { Orientações Curriculares: Diversidades Educa- } \\
\text { cionais. Secretaria de Estado de Educação de } \\
\text { Mato Grosso. Cuiabá: Defanti, 2010. 308p. }\end{array}$ \\
\cline { 2 - 3 } & Mato Grosso do Sul & Não há registro \\
\hline & $\begin{array}{l}\text { Orientações Pedagógicas para o Ensino de } \\
\text { História e Cultura Afro-Brasileira e Indígena } \\
\text { na Rede Pública de Ensino do DF (artigo 26-a } \\
\text { da LDB. DF, 2012. 75p. }\end{array}$ \\
\hline
\end{tabular}

FONTE: Pesquisa de campo, 2018.

\section{Região Sudeste}

Em relação à região Sudeste do Brasil, não foram encontrados materiais publicados sobre a EEQ. Vejamos o quadro 4 a seguir:

QUADRO 4: PRODUÇÃO DE RECURSOS DA REGIÃO SUDESTE

\begin{tabular}{|l|l|l|}
\hline \multirow{4}{*}{ Região } & \multicolumn{1}{|c|}{ Estado } & \multicolumn{1}{c|}{ Documentos } \\
\hline \multirow{4}{*}{ Sudeste } & Espírito Santo & Não há registro \\
\cline { 2 - 3 } & Minas Gerais & Não há registro \\
\cline { 2 - 3 } & Rio de Janeiro & Não há registro \\
\cline { 2 - 3 } & São Paulo & Não há registro \\
\hline
\end{tabular}

FONTE: Pesquisa de campo, 2018.

\section{Região Sul}

Em relação à região Sul do Brasil, não foram encontrados materiais publicados sobre a EEQ no estado do Rio Grande do Sul. Em relação ao estado do Paraná encontramos o Caderno Temático da Diversidade. Esse Caderno Temático, elaborado em 2009, traz uma síntese das ações que compõem a política 
de EEQ no Paraná, contendo artigos do prof. Dr. José Maurício Arruti (PUC$\mathrm{RJ})$, relatórios sobre os índices educacionais das Comunidades Quilombolas e de formações continuadas executadas junto às escolas que atendem essas comunidades e trecho da Proposta Pedagógica Escola Quilombola e Etnodesenvolvimento Sustentável e Solidário.

Sobre o Estado de Santa Catarina, encontramos uma Cartilha cujo objetivo é subsidiar as ações pedagógicas dos professores da rede pública estadual, trazendo, para cada nível ou modalidade de ensino, sugestões para trabalhar as temáticas da diversidade e temas transversais em todas as disciplinas durante todo ano letivo. É importante destacar que a Secretaria de Estado da Educação de Santa Catarina disponibiliza em seu site oficial doze publicações de livros na área da cultura, diversidade, educação intercultural e história e cultura africana e afro-brasileira, no entanto, não são de autoria da secretaria. Vejamos o quadro 5 a seguir:

\section{QUADRO 5: PRODUÇÃO DE RECURSOS DA REGIÃO SUL}

\begin{tabular}{|c|l|l|}
\hline Região & \multicolumn{1}{|c|}{ Estado } & \multicolumn{1}{c|}{ Documentos } \\
\hline Sul & Paraná & $\begin{array}{l}\text { Educação escolar quilombola: pilões, peneiras e co- } \\
\text { nhecimento escolar. Secretaria de Estado da Educa- } \\
\text { ção. Superintendência da Educação. Curitiba: SEED, } \\
\text { 2010. 101 p. }\end{array}$ \\
\cline { 2 - 3 } & Rio Grande do Sul & Não há registro \\
\cline { 2 - 3 } & Santa Catarina & $\begin{array}{l}\text { Diversidade e Temas Transversais: conteúdos, proce- } \\
\text { dimentos e práticas. SEED-SC, 2009, 42 p. }\end{array}$ \\
\hline
\end{tabular}

FONTE: Pesquisa de campo, 2018.

\section{Análise e compreensão dos materiais didáticos produzidos pelos estados brasileiros}

Para análise e discussão sobre a produção de material didático/pedagógico pelos estados brasileiros, foi necessário verificar critérios já validados e estabelecidos pelo MEC, pois, segundo as DCN para a EEQ, essa modalidade de ensino requer pedagogia própria, respeito à especificidade étnico-racial e cultural de cada comunidade, materiais didáticos e paradidáticos específicos que atentem para os princípios constitucionais, a Base Nacional Comum e aos princípios que orientam a educação básica brasileira. Além disso, esses materiais devem ser oferecidos nas escolas quilombolas e naquelas escolas que recebem alunos quilombolas fora de suas comunidades de origem. Segundo Goularte, 
[...] a Lei de Diretrizes e Bases da Educação (LDB) e os Parâmetros Curriculares Nacionais (PCN) são documentos oficiais que orientam o sistema educacional no país. É a partir deles que são elaborados os planejamentos de ensino nas escolas e os critérios de avaliação de livros didáticos pelo Programa Nacional de Livros Didáticos (PNLD). E é com base nesses documentos, ainda, que os livros didáticos aprovados pelo PNLD são orientados (GOULARTE; MELO, 2013, p. 35).

É pertinente destacar que o MEC vem orientando os sistemas de ensino para que ao elaborarem o Plano de Ações Articuladas (PAR $)^{1}$ proponham ações de: a) construção de escolas nas comunidades; b) formação continuada de professores; c) distribuição de materiais didáticos específicos para alunos e professores das referidas comunidades e capacitação de gestores para que a educação escolar quilombola seja implementada no dia a dia da escola (BRASIL, 2018). A análise do livro didático continua a nos fornecer elementos importantes para discutir a diversidade cultural no espaço da escola.

Lembramos que nas DCN para a EEQ, a construção do PPP das escolas e a formação de professores são elementos estruturantes para essa modalidade de ensino. A construção do PPP de forma participativa, envolvendo o coletivo da escola e a comunidade, constitui-se como um processo no qual a escola revela seus compromissos, suas intensões e principalmente a identidade de seus integrantes e deve estar intrinsecamente relacionado com a realidade histórica, regional, politica, sociocultural e econômica das comunidades quilombolas.

O Currículo, assim como o material didático/pedagógico, deve seguir os eixos orientadores gerais da educação brasileira e também se referenciar nos valores das comunidades quilombolas, como a cultura, as tradições, o mundo do trabalho, a terra, a territorialidade, a oralidade e a memória. Deverão se fazer presentes nos currículos a ancestralidade, o trabalho, a estética, as lutas pela terra e pelo território e o desenvolvimento sustentável dessas comunidades (BRASIL, 2015). Nesse sentido, a produção e distribuição de material específico precisa ser feita em diálogo com as realidades locais das várias comunidades existentes em cada município, ou seja, os sistemas estaduais de ensino ao enfatizarem os recursos didático-pedagógicos quilombolas devem seguir as DCN:

Art. 14 A Educação Escolar Quilombola deve ser acompanhada pela prática constante de produção e publicação de materiais didáticos e de apoio

1 O PAR é um plano de metas concretas e efetivas que compartilha competências políticas, técnicas e financeiras para a execução de programas de manutenção e desenvolvimento da educação básica. 
pedagógico específicos nas diversas áreas de conhecimento, mediante ações colaborativas entre os sistemas de ensino (BRASIL, 2012, p. 8).

Portanto, segundo as DCN para a EEQ, a efetivação da produção de material didático-pedagógico fica sob a incumbência da União, do Distrito Federal, dos Estados e Municípios, levando-se em consideração as ações cooperativas para aquisição e distribuição de livros e materiais que abordem a história, cultura africana e afro-brasileira e especificidades das comunidades quilombolas.

A EEQ demanda também a formação de gestores dos sistemas, das escolas das coordenações pedagógicas e das coordenações ou núcleos da diversidade; deve contar também com a presença das lideranças quilombolas que, há muito tempo, reivindicam a participação na elaboração, análise e monitoramento das políticas públicas voltadas para essas comunidades.

Diante desse contexto, e com base nas categorias de análise: a) Conceituação de quilombo; b) Cultura e tradições; c) Mundo do trabalho; d) Terra e território; e) Oralidade e memória, procuramos identificar nos materiais produzidos pelos sistemas estaduais de ensino dos estados brasileiros aspectos pedagógicos e de conteúdo, buscando estabelecer elementos de análise voltados a subsídios pedagógicos. Além disso, a análise avaliativa buscou levar em conta o nível de escolaridade (segmento) ao qual o material se destina. É pertinente ressaltar que se fez necessário deter o olhar para os diferentes sistemas de ensino, ainda que de forma breve, a fim de melhor compreender o papel dos recursos didáticos na construção da proposta de EEQ de cada estado. Visando orientar o trabalho foi organizado o seguinte quadro 6 :

QUADRO 6: CRITÉRIOS DE ANÁLISE

\begin{tabular}{|l|c|c|c|c|}
\hline \multirow{2}{*}{ CATEGORIA } & \multicolumn{3}{c|}{ CRITÉRIO } \\
\cline { 4 - 5 } & A & B & C & D \\
\hline Conceituação de quilombo & & & & \\
\cline { 1 - 1 } Cultura e tradições & \multirow{3}{*}{ Amplo } & Apropriado & Restrito & Inexistente \\
\cline { 1 - 1 } Mundo do trabalho & & & & \\
\cline { 1 - 1 } Terra e território & & & & \\
\hline Oralidade e memória & & & & \\
\hline
\end{tabular}

FONTE: Elaborado pelo autor, 2018.

A partir dos critérios articulados e definidos e, com base nos materiais pedagógicos de EEQ identificados nos estados brasileiros, aplicamos a análise de conteúdo conforme o quadro 7 a seguir: 


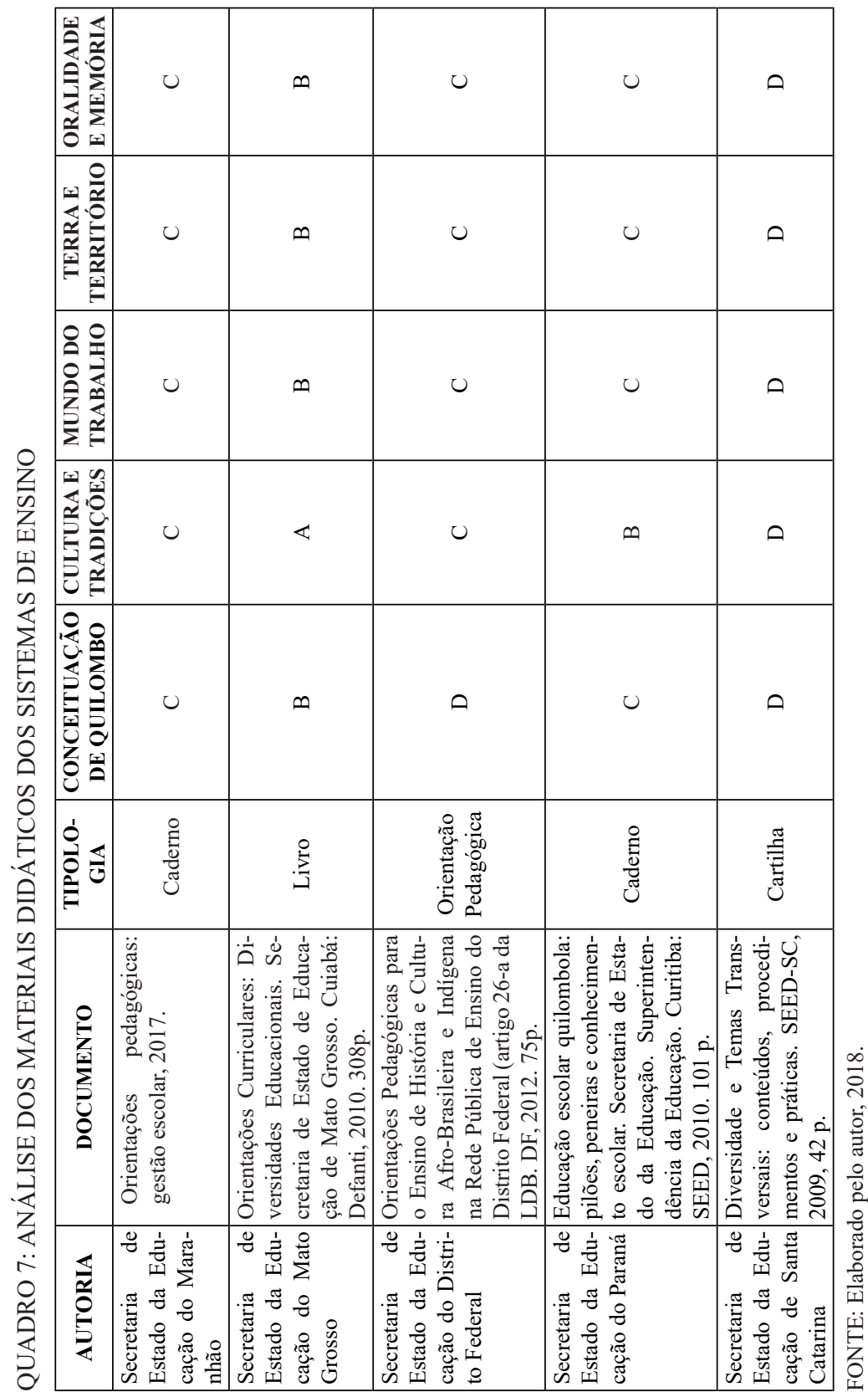


Em uma análise geral, verificamos que os materiais atuais produzidos pelos estados brasileiros não representam uma versão fiel do processo de produção e elaboração do conhecimento científico quanto à EEQ. Apesar de todos os esforços empreendidos até o momento, ainda não se alterou o tratamento dado ao conteúdo presente no material didático levando em consideração todo o contexto histórico e sociocultural das comunidades quilombolas no Brasil.

A literatura educacional brasileira tem destacado a importância da inovação e da aplicação de materiais didáticos diferenciados nos processos de ensino e aprendizagem. Nesse sentido, devemos partir da premissa de que ensinar exige estudo, reflexão além do planejamento das ações propriamente ditas, para uma prática de qualidade.

Assim, entendemos a proposta e/ou o objetivo de construção de um material didático ou mesmo de orientações pedagógicas para a EEQ, a qual consiste em traçar diretrizes e metodologias para essa área específica, buscando aliar os conhecimentos teóricos à prática pedagógica, propiciando assim a articulação e o engajamento das práticas pedagógicas específicas aos conteúdos científicos relacionados a EEQ. Essa articulação pode ser feita por intermédio da compreensão das relações sociais, políticas, econômicas, educacionais e culturais que existem entre as condições de existência dos quilombolas, as experiências e o conhecimento científico. Além disso, esse material deve ter como referencial teórico todo o marco legal que rege a EEQ no Brasil, bem como ser fruto da produção pedagógica realizada pelos educadores da Rede Estadual de Ensino e demais membros das comunidades quilombolas.

Um material didático, quando elaborado de modo coerente, coeso e bem articulado, como processo comprometido com a busca e a construção de novos conhecimentos, levará ao sucesso e/ou ao encaminhamento de problemas reais enfrentados pelos quilombolas em seu cotidiano. Para Larchert e Oliveira (2013), os conteúdos sistematizados não devem ser separados dos conteúdos culturais. Portanto, há que se pensar um material didático em função das possibilidades de uso e aplicabilidade, objetivos de aprendizagem, estrutura do conteúdo, atividade e avaliação, complexidade, linguagem, entre outros.

Em síntese, um material didático bem elaborado precisa estar de acordo com todos os marcos legais da EEQ no Brasil, com o perfil da população-alvo, bem como estar ancorado em princípios que promovam: a) interação; b) cooperação; c) autonomia na construção de novos conhecimentos que favoreçam a realidade sócio-educativo-cultural; d) interdisciplinaridade e transdisciplinaridade.

Um livro e/ou um material pedagógico são materiais importantes para a prática pedagógica como atestam diversas discussões produzidas por autores variados, como nos aponta os estudos de Bittencourt (2007). Assim, um material confeccionado pode melhorar a prática docente sendo um subsídio de 
aplicação pedagógica relevante em diversos momentos do processo de ensino e aprendizagem na prática da sala de aula e fora dela. No entendimento de Rangel, material didático é:

Qualquer instrumento que utilizemos para fins de ensino/aprendizagem é um material didático. A caneta que o professor aponta para os alunos, para exemplificar o que seria um referente possível para a palavra caneta, funciona, nessa hora, como material didático. Assim como o globo terrestre, em que a professora de Geografia indica, circulando com o dedo, a localização exata da Nova Guiné. Ou a prancha em tamanho gigante que, pendurada na parede da sala, mostra de que órgãos o aparelho digestivo se compõe, o que, por sua vez, está explicado em detalhes no livro de Ciências (RANGEL, 2005, p. 25).

É pertinente destacar que a atividade de elaboração de materiais didáticos é um processo que envolve pelo menos quatro etapas específicas: 1) análise das necessidades de aprendizagem dos aprendentes; 2) criação/elaboração de materiais didáticos; 3) implementação; 4) avaliação. Além do mais, o material didático poderá não refletir apenas uma 'voz', nomeadamente a voz do seu autor, mas diversas 'vozes', em especial as daqueles que estão inseridos e partícipes nas comunidades quilombolas. Assim, a criação de um material didático é precedida de escolhas metodológicas, de princípios, de objetivos gerais e específicos e de inúmeras questões teóricas que o seu(s) autor(es) deve(m) ter presente.

\section{Considerações finais}

Concluímos com este estudo "Educação escolar quilombola no Brasil: uma análise sobre os materiais didáticos produzidos pelos sistemas estaduais de ensino" que há um índice muito baixo de produção de recursos e/ou materiais didáticos produzidos pelos sistemas estaduais de ensino no Brasil. Além disso, há uma invisibilidade de políticas públicas de ações afirmativas por parte da maioria dos estados brasileiros, o que vem sendo ratificado pela própria limitação da historiografia da resistência escrava.

O resultado da pesquisa proporcionou uma importante visibilidade nacional quanto à produção específica de material didático em todas as regiões brasileiras, sendo possível detectar, por exemplo, ausência total de produção 
em vários estados (Acre, Amapá, Amazonas, Pará, Rondônia, Roraima, Tocantins, Alagoas, Bahia, Ceará, Paraíba, Pernambuco, Piauí, Rio Grande do Norte, Sergipe, Goiás, Mato Grosso do Sul, Espírito Santo, Minas Gerais, Rio de Janeiro, São Paulo e Rio Grande do Sul) e até mesmo em regiões, como é o caso da região Norte e Sudeste.

Os livros e/ou materiais didáticos analisados apresentaram uma discussão muito restrita e vaga sobre as categorias de análise: a) Conceituação de quilombo; b) Cultura e tradições; c) Mundo do trabalho; d) Terra e território; e) Oralidade e memória, limitando-se, muitas vezes, a abordagens superficiais sobre historiografia do negro no Brasil, deixando de mencionar e destacar a grande contribuição negra para a sociedade brasileira em todas as áreas, o que deixa de contribuir no ensino de conhecimentos a respeito das lutas desse grupo social contra a opressão, desigualdade social e toda e qualquer forma de racismo. Lembramos que uma EEQ pautada nos Direitos Humanos vai além da consciência negra como um privilégio somente de negros e negras, ou seja, é uma prática coletiva de respeito aos seres humanos em suas diversas formas de ver e pensar o mundo.

Observamos que os materiais didáticos produzidos pelos sistemas de ensino estaduais no país atendem, em parte, aos princípios de uma EEQ de qualidade conforme sugerido pelas DCN (2004), no entanto, têm deixado de observar parte dos fundamentos instituídos nas DCN da EEQ (2012) quando não apontam as festividades, atividades econômicas, políticas e sociais do cotidiano quilombola.

Pensar num material didático de EEQ para subsidiar os professores em sala de aula torna-se um desafio, pois, é necessário refletir que muitas vezes o docente desconhece ou nunca ouviu falar sobre essa temática, ou seja, há de se pensar que além de se realizar um produto pedagógico para aluno, torna-se fundamental elaborar um direcionado ao professor como forma de suprir a deficiência da formação inicial ou continuada sobre a EEQ no Brasil.

A elaboração de uma proposta de material didático de EEQ não significa romper com os conhecimentos educacionais tradicionais, mas buscar incorporar a esses conhecimentos a dinâmica do cotidiano, o jogo simbólico da vida, o crescimento e aprimoramento que permeiam as comunidades quilombolas marcados na dimensão do desafio, da luta e do enfrentamento das dificuldades que se materializam em distintos graus nessas comunidades.

Por meio desta pesquisa constatamos que além dos materiais didáticos produzidos pelos sistemas estaduais de ensino serem incipientes, deixam muito a desejar no que diz respeito à participação da comunidade quilombola nesta elaboração e/ou produção, assim também como deixam a desejar nas demonstrações das variedades e diversidades étnicas dos quilombos existentes em nosso país. 
Uma proposta política pedagógica de construção e/ou elaboração de material didático precisa ser construída coletivamente, envolvendo todos os segmentos da comunidade regional e local. Precisa garantir os princípios pautados na educação antirracista. Além disso, deve ser livre de violência simbólica, ou seja, independente das mais variadas situações em que negros e brancos possam se encontrar, devem ser tratados de maneira igualitária, com equidade de direitos. Assim como todas as formas depreciativas de um povo em detrimento de outro devem ser abolidas.

Confrontando os estudos recentes sobre resistência escrava com os livros didáticos e/ou materiais analisados, constatamos que há uma distância do que é produzido pelos sistemas de ensino estaduais e o que chega de fato às comunidades quilombolas. A maioria dos materiais segue um raciocínio tradicional sobre os quilombos, dando uma visão simplista e reducionista sobre esses movimentos de resistência. Por conta dessa invisibilidade do negro e da negra nos livros e/ ou materiais didáticos da Educação Básica, urge a necessidade de um produto pedagógico sobre essa temática, a fim de dar subsídios à prática do professor em sala de aula. É pertinente destacar que os conteúdos da educação formal só terão sentido para os educandos quilombolas se a vida cotidiana, sua história e seus valores culturais e religiosos fizerem parte do currículo escolar do quilombo.

De modo geral, de acordo com o que foi proposto no projeto de pesquisa do estágio de pós-doutoramento, foram obtidos os resultados almejados - embora haja escassez de produções por partes dos diversos estados brasileiros -, os quais certamente contribuirão, de forma direta, na própria atuação docente e, de forma indireta, na consolidação da área de conhecimento de Educação para as relações étnico-raciais, como foco e enfoque específicos na EEQ.

\section{REFERÊNCIAS}

BARDIN, L. Análise de conteúdo. Trad. Luís Antero Reto e Augusto Pinheiro. Lisboa: Edições 70, 2002.

BITTENCOURT, C. (Org.). Livro didático: educação e história. In: SIMPÓSIO INTERNACIONAL DO LIVRO DIDÁTICO, São Paulo, 2007. Resumos... São Paulo: FAPESP/Capes, 2007.

BRASIL. Constituição da República Federativa do Brasil. Brasília, DF: Senado Federal, 1988. Diário Oficial da União, Assembleia Nacional Constituinte, Brasília, DF, 05 out. 1988. 
BRASIL. Lei n ${ }^{\circ}$ 9.394, de 20 de dezembro de 1996. Estabelece as diretrizes e bases da educação nacional. Diário Oficial da União, Poder Legislativo, Brasília, DF, 23 dez. 1996.

BRASIL. Lei n ${ }^{\circ}$ 9.475, de 22 de julho de 1997. Dá nova redação ao art. 33 da Lei ${ }^{\circ}$ 9.394, de 20 de dezembro de 1996, que estabelece as diretrizes e bases da educação nacional. Diário Oficial da União. Brasília, DF, 23 jul. 1997.

BRASIL. Lei ${ }^{\circ} 10.639$, de 9 de janeiro de 2003. Altera a Lei no 9.394, de 20 de dezembro de 1996, que estabelece as diretrizes e bases da educação nacional, para incluir no currículo oficial da Rede de Ensino a obrigatoriedade da temática "História e Cultura Afro-Brasileira", e dá outras providências. Diário Oficial da União. Brasília, DF, 10 jan. 2003.

BRASIL. Ministério da Educação (MEC). Diretrizes curriculares nacionais para a educação das relações étnico-raciais e para o ensino de História e Cultura Afro-brasileira e Africana. Diário Oficial da União, Brasília, DF, 22 jun. 2004.

BRASIL. Governo do Estado de Santa Catarina. Secretaria de Estado da Educação e do Desporto. Diretoria de Educação Básica e Profissional. Diversidade e Temas Transversais: conteúdos, procedimentos e práticas, 2009.

BRASIL. Ministério da Educação (MEC). Educação escolar quilombola. Diário Oficial da União, Brasília, DF, 09 jul. 2010.

BRASIL. Governo do Estado de Mato Grosso. Secretaria do Estado da Educação. Gerência da Diversidade. Orientações Curriculares: Diversidades Educacionais. Cuiabá: Defanti, 2010.

BRASIL. Governo do Estado do Paraná. Secretaria de Estado da Educação. Educação escolar quilombola: pilões, peneiras e conhecimento escolar. Secretaria de Estado da Educação. Superintendência da Educação. Curitiba: SEED, 2010, 101 p. (Caderno temático da diversidade).

BRASIL. Ministério da Educação (MEC). Conselho Nacional de Educação. Resolução $n^{\circ} 08$, de 20 de novembro de 2012. Parecer CNE/CEB n 16 de 2012. Define diretrizes curriculares nacionais para educação escolar quilombola na educação básica. Diário Oficial da União, Brasília, DF, 20 nov. 2012.

BRASIL. Governo do Estado do Maranhão. Secretaria do Estado da Educação (SEDUC). Escola Digna. Caderno de orientações pedagógicas: gestão escolar, 2017. Disponível em: < http://www.educacao.ma.gov.br/files/2017/05/apostila-final-produc\%CC\%A7a\%CC\%83o.pdf>. Acesso em: 14 nov. 2017.

BRASIL. Ministério da Educação (MEC). Portal MEC. Plano de ações articuladas (PAR). Disponível em: <http://simec.mec.gov.br/cte/relatoriopublico/principal.php>. Acesso em: 28 set. 2018.

BRASIL. Governo do Distrito Federal. Secretaria do Estado da Educação. Orientações Pedagógicas para o Ensino de História e Cultura Afro-Brasileira e Indígena na Rede 
Pública de Ensino do DF (artigo 26-a da LDB). Disponível em: http://www.cre.se.df. gov.br/ascom/documentos/abril17/o_p_artigo_26A_17_09_2012.pdf. Acesso em: 03 dez. 2017.

CUSTÓDIO, E. S. Um olhar sobre as propostas de educação escolar quilombola no Brasil a partir de referenciais curriculares e materiais didáticos estaduais. 2018. 112 f. Relatório (Pós-Doutoramento) - Programa de Pós-Graduação em Educação, Universidade Federal do Amapá. Macapá: PPGED/UNIFAP, 2018.

FREIRE, P. A educação na cidade. São Paulo: Cortez, 1991.

FONSECA, J. J. S. da. Metodologia da pesquisa cientifica. Fortaleza: UEC, 2002.

GOULARTE, R. da S.; MELO, K. R. de. A lei 11.645/08 e a sua abordagem nos livros didáticos do ensino fundamental. Revista Entretexto, Londrina, v. 13, n. 2, p. 33-54, 2013. Disponível em: <http://www.uel.br/revistas/uel/index.php/entretextos/article/ view/16035>. Acesso em: 03 dez. 2017.

LARCHERT, J. M.; OLIVEIRA, M. W. de. Panorama da Educação Quilombola no Brasil. Políticas Educativas, Porto Alegre, v. 6, n. 2, p. 44-60, 2013. Disponível em: $<$ https://seer.ufrgs.br/Poled/article/viewFile/45656/28836>. Acesso em: 03 dez. 2017.

MELUCCI, A. Por uma Sociologia Reflexiva: pesquisa qualitativa e cultura. Petrópolis: Vozes, 2005.

MINAYO, M. C. de S. O desafio do conhecimento: pesquisa qualitativa em saúde. 11. ed. São Paulo, HUCITEC, 2008.

RANGEL, E. de O. Avaliar para melhor usar - avaliação e seleção de materiais e livros didáticos. In: BRASIL. MEC. Salto para o Futuro.TV Escola: Materiais didáticos: escolha e uso. Boletim 14, agosto 2005. Disponível em: $<$ http://tvbrasil.org.br/fotos/salto/ series/151007MateriaisDidaticos.pdf $>$. Acesso em: 6 maio 2018.

Texto recebido em 08 de novembro de 2018 .

Texto aprovado em 22 de janeiro de 2019. 